\title{
Penetration of a woven CFRP laminate by a high velocity steel sphere impacting at velocities of up to $1875 \mathrm{~m} / \mathrm{s}$
}

\author{
PJ Hazell*, A Cowie, G Kister, C Stennett, G A Cooper \\ Cranfield Defence and Security, Cranfield University, Shrivenham, Swindon, Wiltshire, \\ SN6 8LA
}

\begin{abstract}
The impact of a woven 6 mm thick CFRP laminate has been subjected to impact by an annealed steel sphere up to velocities of $1875 \mathrm{~m} / \mathrm{s}$. It was observed that above a threshold impact energy, the percentage of kinetic energy dissipated by the laminate was constant. Further, the level of damage, as measured by C-Scan and through-thickness microscopy remained constant as the impact energy was increased. However, the size of the hole formed increased. This suggested that the energy transferred to the target in the velocity range of interest became independent of the delamination. Consequently, the main energy transfer mechanism at the high velocities of impact is thought to be due to the cavity expansion and more importantly, the kinetic energy of the particulates.
\end{abstract}

Keywords: Carbon fibre; energy dissipation; penetration mechanisms; damage mechanics.

*p.j.hazell@cranfield.ac.uk ; Tel: +44 (0) 1793785731 


\section{INTRODUCTION}

The high velocity impact response of CFRP materials is of particular interest to aircraft manufacturers who are concerned with attack from fragmenting munitions. These fragmenting munitions can accelerate a dispersion of metallic projectiles to velocities of c. $2000 \mathrm{~m} / \mathrm{s}$ by means of a detonating high explosive charge. Consequently there is a need to understand the energy absorption and damage mechanisms that occur when such projectiles strike aircraft-grade CFRP panels. Very little work has been done on examining the impact response of carbon fibre composite laminates at impact velocities above $500 \mathrm{~m} / \mathrm{s}$. This is not surprising due to their very low ballistic performance [1] and apart from the impact and penetration by fragmenting munitions, there is little application relevant to this velocity regime. There has been however interest in velocities in excess of $2000 \mathrm{~m} / \mathrm{s}$ due to the application of these structures to space vehicles [2,3].

Cantwell and Morton [1] have shown that the response of a CFRP panel to these two very different loading regimes was quite different. On the one hand, for low velocity impact, the size and shape of the panel determined its energy absorbing capability. Whereas on the other hand, high velocity projectiles induced a localised response in the target that did not depend on the areal size of the target.

Hazell et al. [4] have previously shown that below an impact energy of $500 \mathrm{~J}$, the energy absorbed by $3 \mathrm{~mm}$ and $6 \mathrm{~mm}$ plates dropped off and appeared to approach an asymptotic level. For a 6-mm thick CFRP panel, the level of damage also appeared to drop off and approached a constant level whereas with the $3 \mathrm{~mm}$ target the level of damage appeared to be constant regardless of the impact energy. The observed constant 
level of damage in the $3 \mathrm{~mm}$ panel was probably due to the fact that the level of damage had already plateaud before the minimum impact velocity used in these experimental trials was reached. Indeed, Tanabe et al. [5] have shown that the drop-off in areal damage occurred at an impact energy of $20 \mathrm{~J}$ for 4 and 5-mm diameter spheres impacting c. 2-mm thick CFRP panels. This was at a much lower impact energy than was tested in [4]. Tanabe and Aoki [6] have studied the impact response of a variety of carbonfibre-based laminates at velocities between 150-1300 m/s. In their work, they employed embedded PVDF stress gauges and constantan strain gauges to assess the stress and strain response of the materials when subjected to impact and penetration. They found that the maximum stress generated in the CFRPs depended on the nature of the reinforcing fibres. Further, they noted that above a critical measured stress, the fracture of the CFRP was "fluid-like" in that comminution of the material had occurred.

Fujii et al. [7] impacted several kinds of CFRP laminate specimens consisting of different carbon fibres, interlaminate sequences, configurations and thicknesses. They also observed, what they described as a "fluid-like" failure of the laminate. Notably, they showed that there was no clear difference in the energy absorbing abilities between crossply specimens and specimens consisting of a five-harness woven cloth. They also showed that the delamination width depended on impact energy.

Hammond et al. [8] studied the response of relatively thin (1.8-2.5 mm) CFRP panels of different symmetrical lay-ups struck by a $12.7 \mathrm{~mm}$ steel projectile that had an average velocity of $474 \mathrm{~m} / \mathrm{s}$. Here they showed that microstructural damage mechanisms were similar regardless of lay-up with the major difference being the volume over which the damage was spread. 
Recently Lopez-Puente et al. [9] have presented work on the normal and oblique penetration of CFRP laminates using both a gas gun and the finite element commercial code ABAQUS/Explicit. They showed that the maximum damage inflicted by the projectile at the ballistic limit was produced at normal incidence. Furthermore, below the ballistic limit, the extent of damage for normal impact was larger than that for the oblique impact. However, the extent of damage at higher velocities appeared to be greater for oblique impacts. Lopez-Puente et al. [10] have also studied the effect of low temperature on the impact response of these materials. They showed that quasi-isotropic tape laminates were less effective against impact than woven laminates due to the different flexural behaviour of the plies. They also showed that temperature has no effect on damage extension and consequently for aerospace applications, the damage extension could be determined by impact tests at room temperature.

In this study, we have examined the response of a single thickness of woven CFRP to impact and penetration by a fully annealed stainless steel sphere between the velocity regime of $141 \mathrm{~m} / \mathrm{s}$ and $1875 \mathrm{~m} / \mathrm{s}$. The objective of this study was to interrogate the behaviour of the CFRP laminate when subjected to impact in this velocity regime and to measure the energy dissipated by the laminate when completely penetrated. This work is part of a wider study on the dynamic behaviour of woven CFRP laminates. 


\section{EXPERIMENTAL METHODOLOGY}

Materials used

The materials chosen for this study were woven CFRP laminates that were manufactured using the resin transfer moulding (RTM) method and supplied by Short Brothers plc, Belfast. These laminates were chosen because they are commonly used in the aerospace industry. All individual panels were manufactured with Hexcel G0926 Carbon Fabric with a 5 harness satin weave. The resin used was a Hexcel RTM6 epoxy system cured for 1 hour 40 minutes at $180{ }^{\circ} \mathrm{C}$ and at a pressure of 100 psi. The shock behaviour of this particular epoxy resin system has previously been reported in [11]. The CFRP panel was $6 \mathrm{~mm}$ thick and made from 16 plies with the lay-up in sequence from impact face to rear face: $0 / 90, \pm 45, \pm 45,0 / 90, \pm 45, \pm 45,0 / 90,0 / 90, \pm 45,0 / 90, \pm 45$, $0 / 90, \pm 45,0 / 90, \pm 45,0 / 90$. The effect of the asymmetrical layup on ballistic performance has previously been reported in [4] and has been shown to be negligible. The density of the CFRP material, measured using a Micrometrics AccuPyc 1330 gas pycnometer, was $1.512 \mathrm{~g} / \mathrm{cc} \pm 0.001 \mathrm{~g} / \mathrm{cc}$. The dynamic behaviour of this type of laminate subjected to flyer-plate testing has been reported both by Millett et al. [12] and ourselves [13]. The mass fraction of the reinforcement was measured using the acid digestion method according to ASTM D 3171-6, Procedure B. [14] and was found to be $69.7 \pm 1.0 \%$. 
Impact testing

The projectile used was a fully annealed stainless steel sphere $(\varnothing 11.97 \mathrm{~mm} \pm 0.01$ $\mathrm{mm}$; mass $=7.165 \mathrm{~g} \pm 0.001 \mathrm{~g} ; \mathrm{VHN}=127)$. The balls (AISI type 304) were fully annealed in air at $1050^{\circ} \mathrm{C}$ to provide equiaxed austenite grains and consequently isotropic behavior. The yield strength of this steel at $21^{\circ} \mathrm{C}$ is $450 \mathrm{MPa}$ with an ultimate tensile strength of $675 \mathrm{MPa}$ [15]. The projectile was fired from ELVIS, a single stage $\varnothing 22-\mathrm{mm}$ gas-gun for velocities of less than $400 \mathrm{~m} / \mathrm{s}$. To achieve the higher velocities a $30 \mathrm{~mm}$ single stage gas gun and a 30 mm RARDEN cannon were employed. With the $30-\mathrm{mm}$ gas gun, a baffle plate was employed behind the sabot stripper to remove any sabot debris that inadvertently made its way through the sabot stripper behind the projectile. Target specimens were cut from supplied material into a minimum dimension of $150 \mathrm{~mm} \times 150$ mm squares and secured at the top and bottom of the target.

Impact velocity was measured by either using foil gauges or high speed video camera; the residual velocity of the projectile was measured using the camera. The energy transferred to the panel was assessed by measuring the impact velocity and the residual velocity of the projectile to an accuracy of $<1 \%$. Two high speed video cameras were used: a Phantom 7 running at 18,000 pictures-per-second with an exposure time of $2 \mu$ s and a Photron Ultima 512 running at 16,000 pictures-per-second with an exposure time of $3 \mu \mathrm{s}$. The energy transferred to the target $\left(E_{t}\right)$ was calculated from

$$
E_{t}=\frac{1}{2} m_{p}\left(v_{i}^{2}-v_{r}^{2}\right)
$$


where $m_{p}$ is the mass of the projectile, and $v_{i}$ and $v_{r}$ are the impact and residual velocities. Consequently, the percentage change in kinetic energy $\left(\Delta \mathrm{E}_{\mathrm{f}}\right)$ was calculated using

$$
\Delta E_{f}=\frac{E_{t}}{E_{i}} \times 100
$$

where $E_{\mathrm{i}}$ is the kinetic energy of the projectile prior to impact.

Parallax was taken into account by knowing the distances from the camera lens to the axis of penetration and from the axis of penetration to fiduciary markers. Debris that was ejected from the targets was recovered using multiple layers of cotton cloth. The experimental set-up for the high velocity shots using the 30 -mm single-stage gas-gun is shown below in Figure 1.

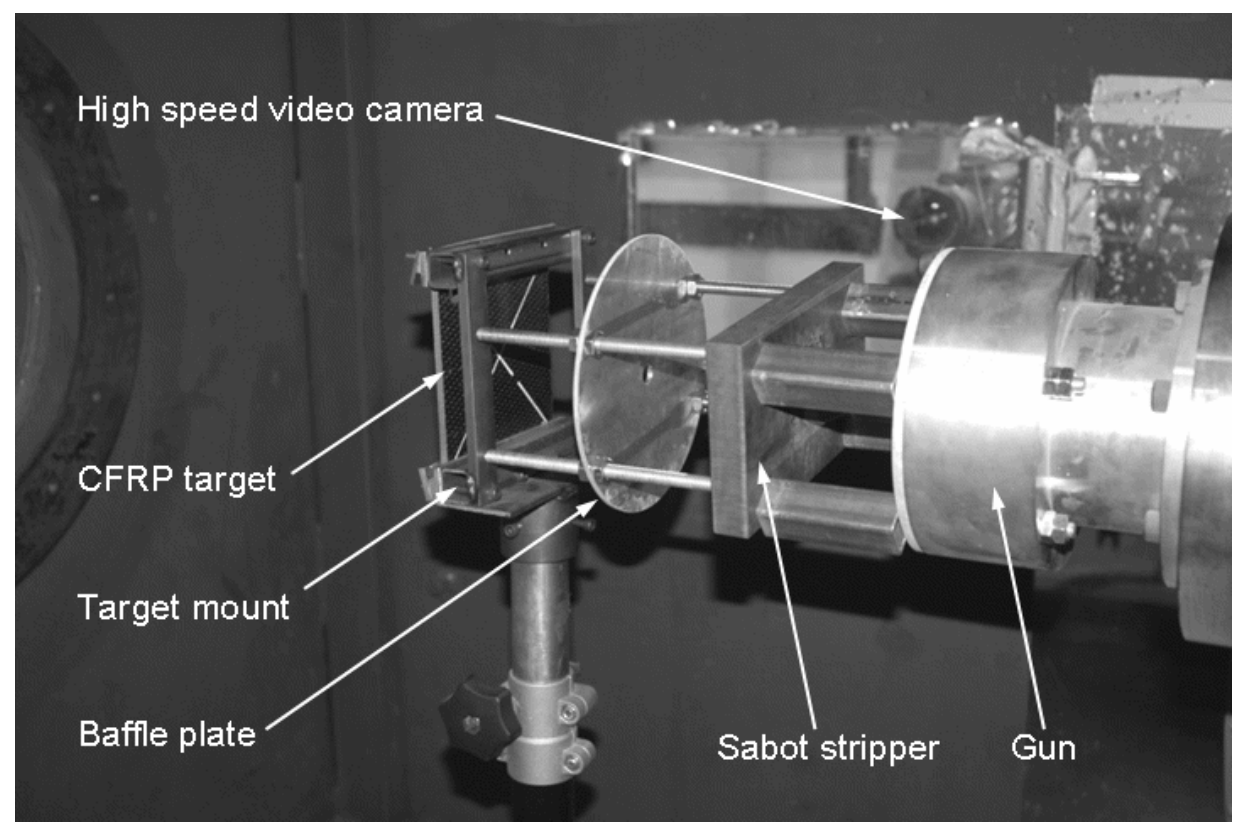

Figure 1: Experimental set-up for the high velocity shots (30-mm single-stage gas gun). 
The extent of damage in the perforated composites was assessed by doing C-scans and by sectioning the CFRP panel to analyse the extent of through-thickness damage; microscopy was also carried out on the ejecta using a LEO 435VP scanning electron microscope. The C-scans were carried out using a glass reflector technique with a $5 \mathrm{MHz}$, 50mm crystal focus transducer. The scans were carried out by Midas NDT Systems Ltd. using a $1 \mathrm{~mm}$ grid and a scan speed of $100 \mathrm{~mm} / \mathrm{s}$. 


\section{RESULTS AND DISCUSSION}

Change in energy

The percentage change in the kinetic energy (KE) for the $6 \mathrm{~mm}$ targets is shown below in Figure 2. We have also included data that was reported in reference [4] using an identical experimental set-up.

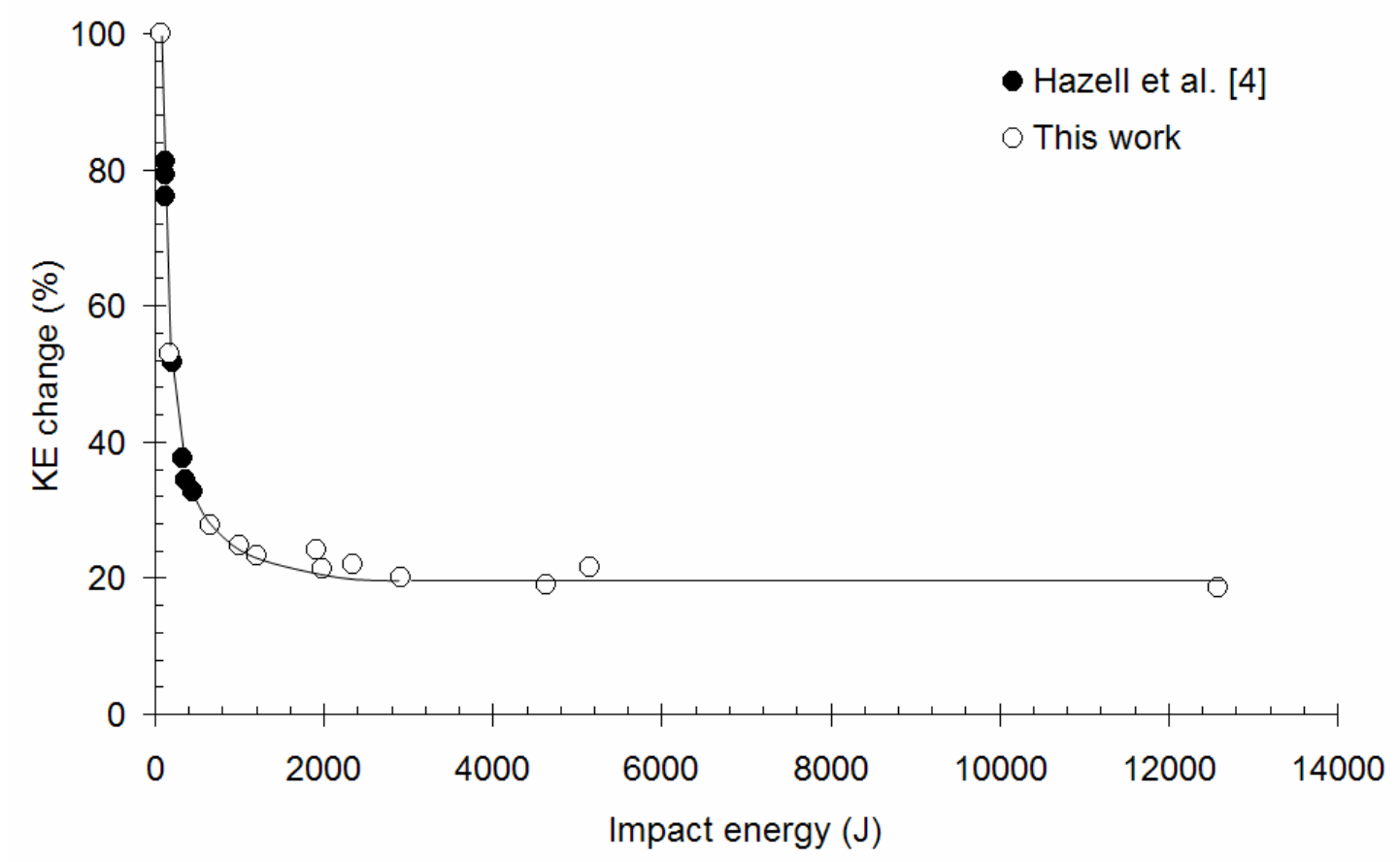

Figure 2: Percentage change in KE due to the perforation of the CFRP laminates.

There are a few things to note here.

Firstly, we have reduced the impact energy from the lowest result reported in [4] to $71 \mathrm{~J}(141 \mathrm{~m} / \mathrm{s})$. This resulted in the projectile being stopped whereas with an impact energy of $115 \mathrm{~J}(179 \mathrm{~m} / \mathrm{s})$ the target was perforated. Consequently, the ballistic limit for this 6-mm thick woven CFRP laminate is between $141 \mathrm{~m} / \mathrm{s}$ and $179 \mathrm{~m} / \mathrm{s}$ for the type of 
projectile used in this study and consequently the perforation threshold energy is inbetween $71 \mathrm{~J}$ and $115 \mathrm{~J}$.

Secondly, for impact energies up to $1000 \mathrm{~J}$ the percentage of kinetic energy absorbed rapidly reduces with increasing kinetic energy of the projectile. This is due, in part, to the change in penetration mechanisms of the projectile from that of causing petalling where the fibre tows are loaded in tension, to causing compression / shear failure in the target [4]. For the normal incidence targets it was evident that at lower velocities the failure is dominated by petalling whereas at higher velocities the failure of the target is dominated by plug formation.

Thirdly, it is clear that over the velocity range of interest in this research, the percentage of KE absorbed is almost constant above an impact energy of around $2000 \mathrm{~J}$.

\section{Perforation mechanisms}

Increasing the energy of impact from $71 \mathrm{~J}$ to $177 \mathrm{~J}$ resulted in perforation of the composite target. Figure 3 shows the impact, penetration and perforation of a CFRP panel that has been struck by the projectile with an impact energy of $177 \mathrm{~J}$. At this level of impact energy, the perforation was dominated by the petalling of the rear surface plies. During the initial stages of penetration, bulging was evident and eventually tensile failure ensued and the projectile was able to perforate. The petals that were formed were pushed aside by the projectile; some of the rear surface plies were ejected during penetration. Eventually, the penetration channel formed by the projectile was closed as the remaining 
petals relaxed resulting in a penetration channel that was less than $12 \mathrm{~mm}$ in diameter (the diameter of the steel sphere).

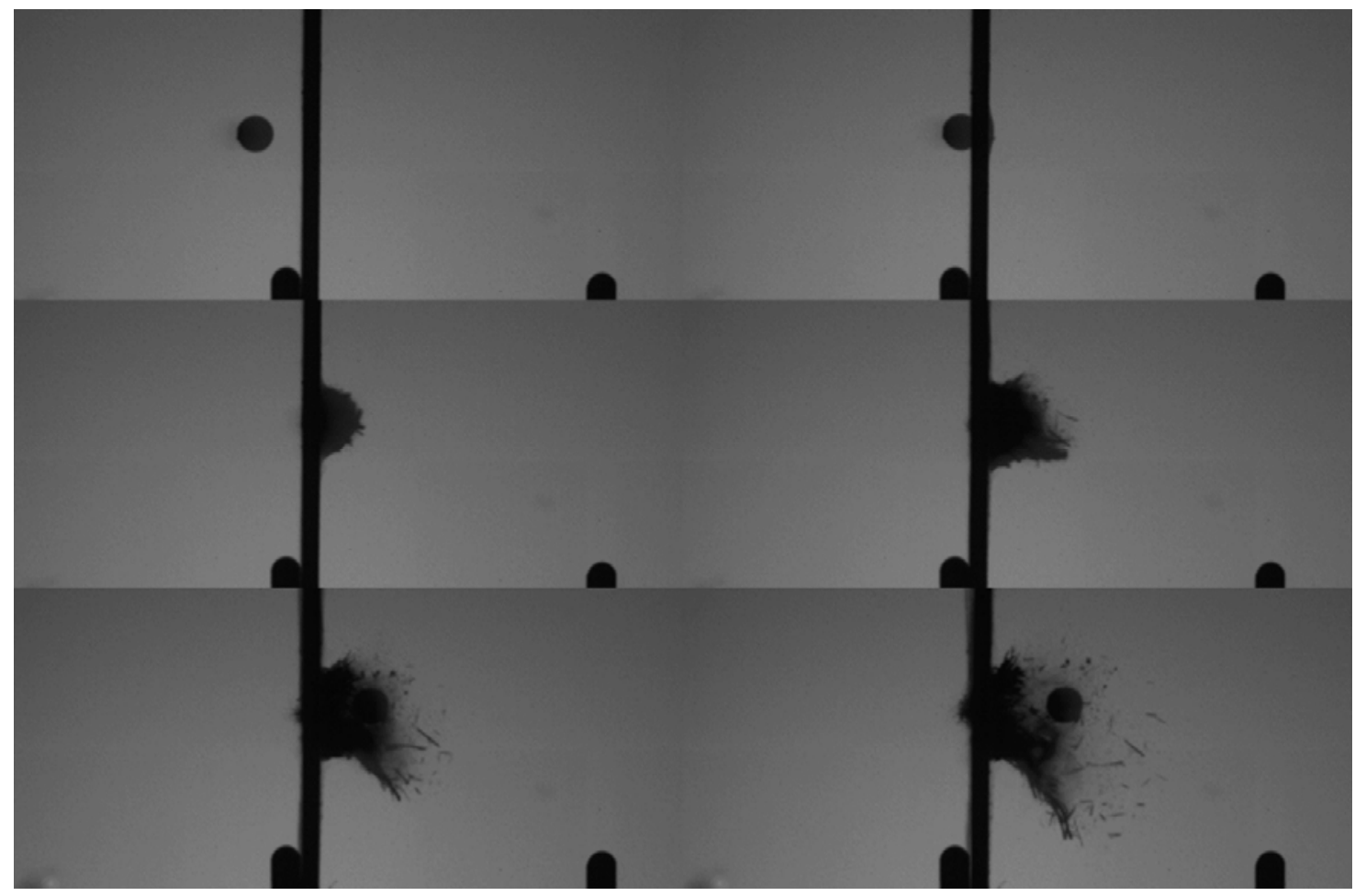

Figure 3: Penetration of the CFRP laminate panel; impact energy $=177 \mathrm{~J}(223 \mathrm{~m} / \mathrm{s})$. Filmed at 18,000 frames-per-second with an exposure of 2 ss per frame.

Increasing the impact energy to $659 \mathrm{~J}$ resulted in a different target response. Post mortem interrogation of the target revealed that a clear penetration channel had been formed that was similar in diameter to that of the steel projectile (c. $12 \mathrm{~mm}$ ). Furthermore, a plug of CFRP was soft captured by layers of cotton rags located behind the target. Previous work presented in [4], has shown that as the impact energy was increased, the perforation mechanism in these types of laminates changed from that which was dominated by petalling to a mechanism that was dominated by a conicallyshaped plug-formation. Indeed, other researchers have also observed plug formation 
during the penetration of CFRP materials. Li and Sun [16] noted plug formation in thin CFRP laminates that had been struck by a blunt-ended projectile at relatively low velocities ( $<100 \mathrm{~m} / \mathrm{s})$. Cantwell and Morton [17] have previously shown that during the perforation of a thin CFRP material, a frustum-shaped fracture zone is formed. This observation is consistent with the conically shaped plugs that we soft-captured. Interestingly, we recovered plugs up to and including impact energies of $1983 \mathrm{~J}$.

A recovered plug from an impact at $1983 \mathrm{~J}$ is shown below in Figure 4. The surfaces seen in this micrograph correspond to the fracture surfaces of the different plies in the composite target.

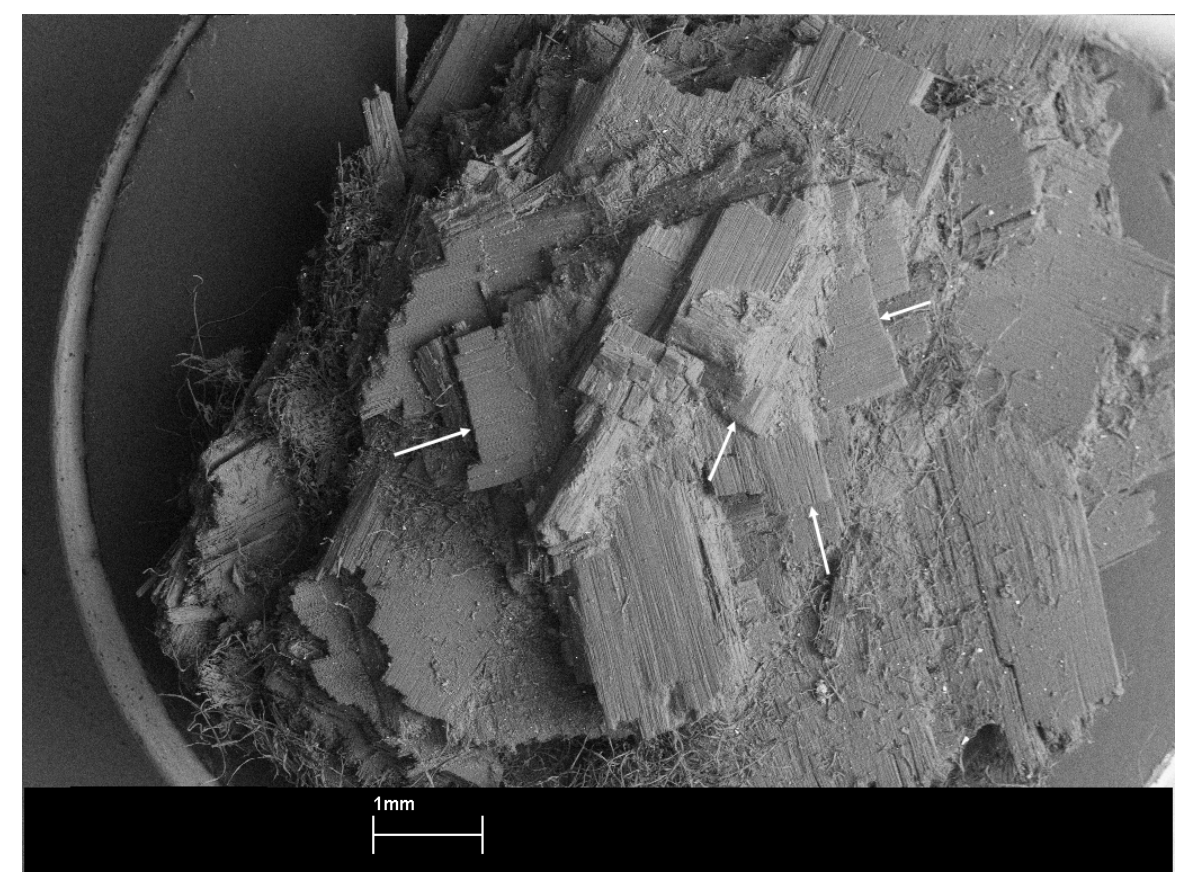

Figure 4: Micrograph of a recovered plug; impact energy = $1983 \mathrm{~J}(744 \mathrm{~m} / \mathrm{s})$.

The analysis of the SEM micrograph of the recovered plug in Figure 4 showed that the fibre tows on the top surfaces of the recovered plug appeared to have undergone a shear type failure which is characterised by the relatively clean fracture of the fibre tows. 
These are highlighted by the arrows. On the other hand, the rear surface tows of the plug appeared to have considerably more jagged failure surfaces. Figure 5 shows a close up of one such failure surface (indicated by the arrow) on a tow towards the rear of a plug recovered from a target that was impacted with an energy of $662 \mathrm{~J}(430 \mathrm{~m} / \mathrm{s})$. The rear tows appeared to have been subjected to fibre pull out and is characteristic of tensile type of failure observed by Hatta et al. [18] under quasi-static loading conditions. Both the compressive shear failure and tensile failure in plug formation have been observed previously by Hazell et al. [4]. Here it was deduced that the simultaneous shear failure of the front tows with tensile failure of the rear tows was not possible unless extensive dishing had occurred in the target.

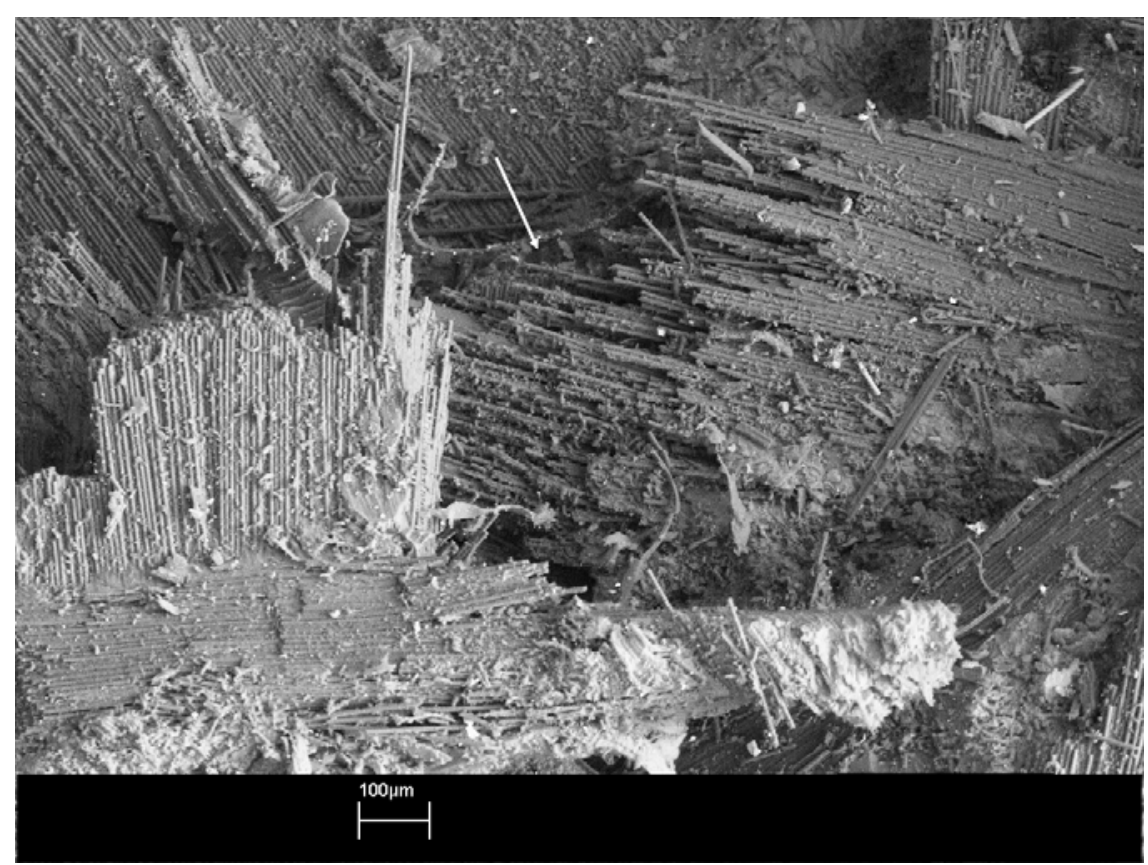

Figure 5: Micrograph of tensile failure of fibre tows in a plug recovered from the laminate impacted at $662 \mathrm{~J}(430 \mathrm{~m} / \mathrm{s})$. 
On all plugs recovered, it was notable that matrix failure had occurred. At the top of the plug where the projectile was in contact with the CFRP laminate, the micrographs revealed that the fibre had been exposed. Figure 6 shows an example of exposed fibres on the plug recovered from an impact at $1983 \mathrm{~J}(744 \mathrm{~m} / \mathrm{s})$. The left hand micrograph shows that the fibres have been readily exposed and are clearly defined. Whereas the right hand micrograph shows the fibres close to a tow failure; the visible debris is particulated RTM6 epoxy resin. Notably, this resin is strong yet brittle when fully cured (strain-to-failure $=3.4 \%$ [19]) and consequently would be susceptible to brittle failure during projectile penetration.

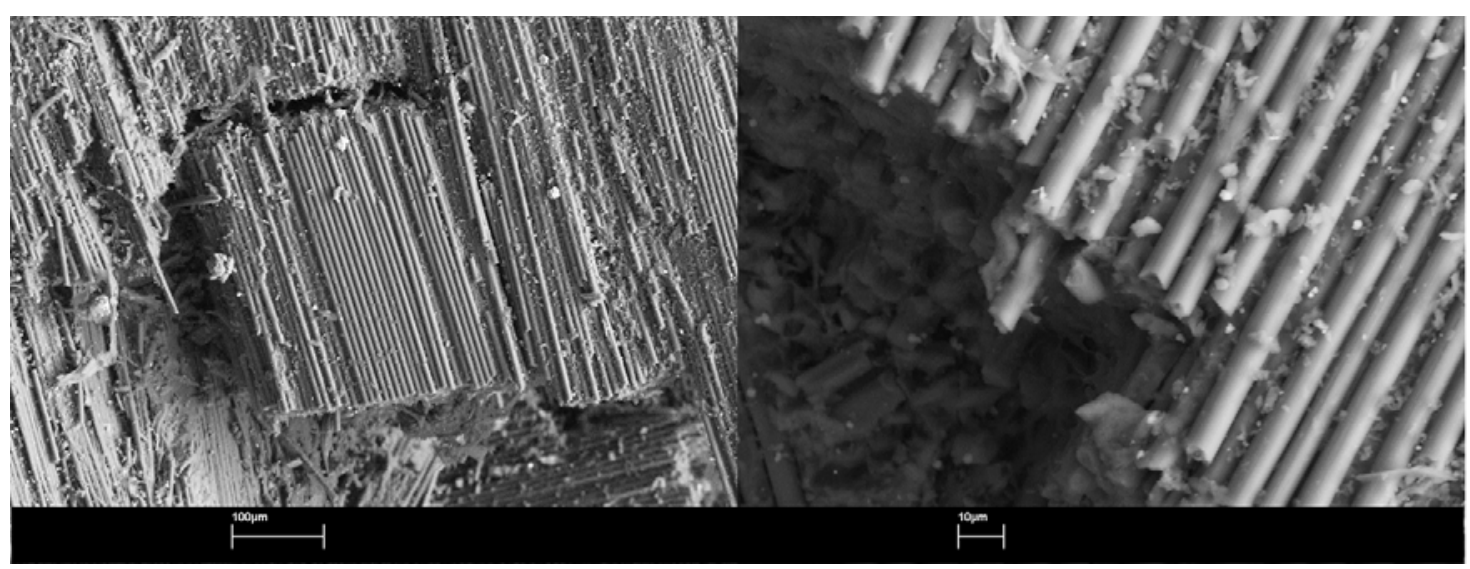

Figure 6: Micrographs of a plug recovered from the impact at $1983 \mathrm{~J}(744 \mathrm{~m} / \mathrm{s})$ showing the exposure of the fibre tows due to failure of the matrix.

Increasing the impact energy beyond $1983 \mathrm{~J}$ appeared to reveal a different response in the target in this experimental programme. We should point out that this energy level is unlikely to be a clearly defined transition from one response to another but rather an energy level around which a gradual change in target response is expected. Increasing the impact energies above $1983 \mathrm{~J}$ resulted in no plug being captured in the 
cotton rags or observed in the high speed video footage. Furthermore, above this impact energy, it was apparent that little-to-no drop-off in percentage change in kinetic energy was observed with increasing impact energy (see Figure 2).

Figure 7 shows the sequence of events as the projectile impacts, penetrates and perforates a target; the impact energy was $5150 \mathrm{~J}$ (1199 m/s). As the projectile contacts the CFRP material, light is emitted (frame B). At $125 \mu$ s a plume of particulated CFRP material has been formed, the forward front of which precedes the projectile. Material is ejected backwards from the impact surface. At $187.5 \mu$ s the projectile starts to emerge from the cloud of dust. The material ejected from the impact surface of the panel appears to be moving at a lower velocity than the material ejected from the rear surface. At 250 $\mu$ s (frame E) the projectile is clearly defined. The large fragments formed maintain a velocity similar to the projectile (c. $1062 \mathrm{~m} / \mathrm{s}$ ) whereas the large volume of lighter particles are slowed. By $312.5 \mu$ s (frame F) the lighter particles are moving with an average linear velocity of $200 \mathrm{~m} / \mathrm{s}$. 
Int. J. of Impact Engng. Vol. 36 (9), pp. 1136-1142

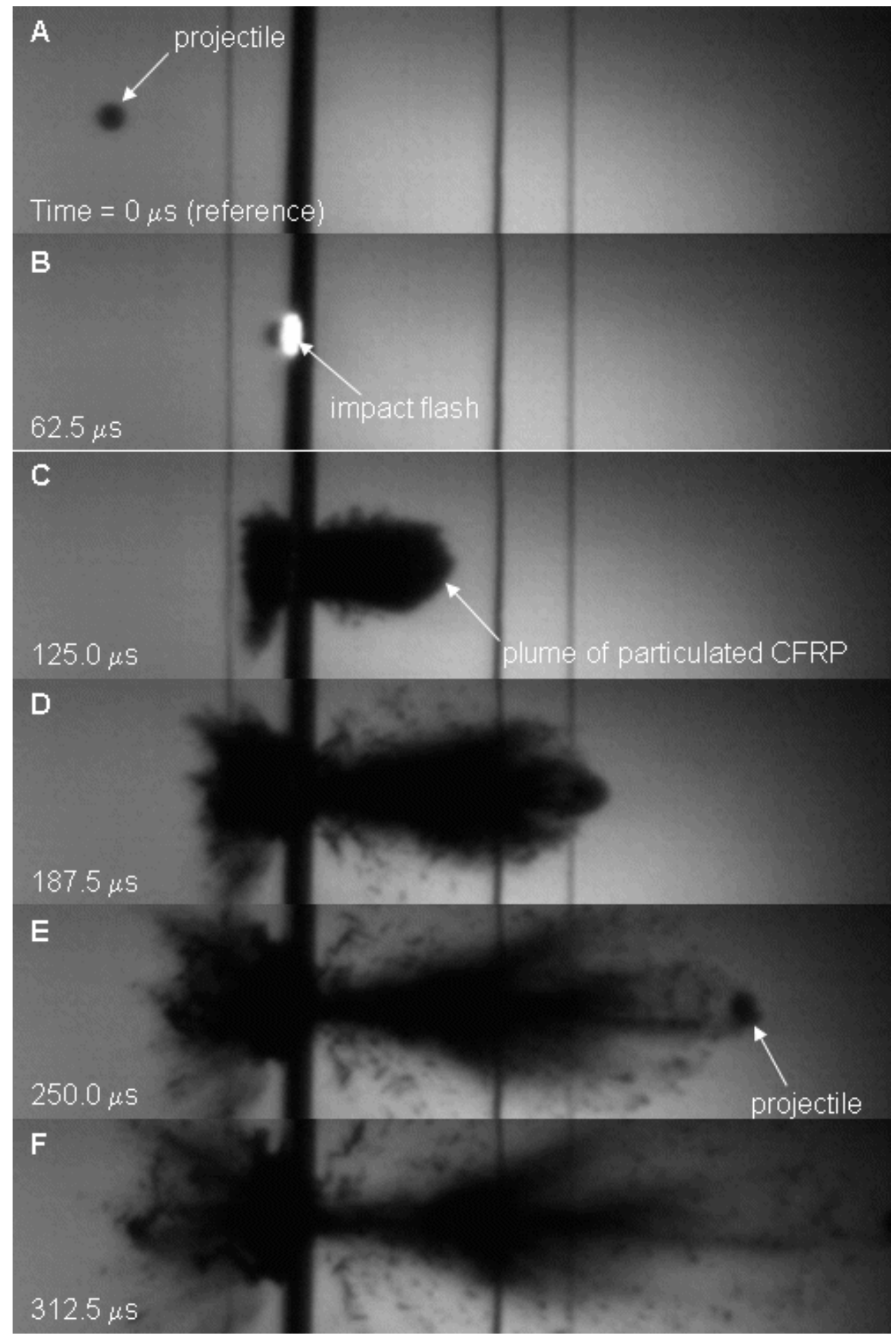

Figure 7: High speed video images taken at 16,000 frames-per-second showing the perforation of a 6$\mathrm{mm}$ CFRP laminate; impact energy = $5150 \mathrm{~J}(1199 \mathrm{~m} / \mathrm{s})$. 
The high speed video footage revealed that there was considerable particulation of the CFRP laminate; no plug was captured in the soft rags located behind the target or observed in the video footage. The fact that the CFRP laminate has been broken down into much smaller fragments than was observed at the lower velocity lends weight to the view that the resin is extensively damaged and particulated as the impact energy is increased.

\section{Damage assessment}

The targets were C-scanned to examine the extent of the internal damage to the panels. An image analyzer program was used to measure the damage zone when the signal attenuation was greater than $5 \mathrm{~dB}$. For the targets impacted at a velocity close to the ballistic limit, the cavity had partially closed therefore giving a misleading representation of the size of the penetration channel. Consequently, the results presented in Figure 8 include the hole size and represent the total area of damage. It was noted that in the majority of the normal incidence impact cases the area of delamination was mostly circular. However, on a number of occasions, the composite was damaged by small amounts of low density sabot debris leading to non-circular pattern of damage. In these cases, an estimate of the damage caused by the sabot debris was calculated by using a circular template - the diameter of which contacted the periphery of the damage at least on two points. In these cases, the total damage (including sabot impact damage) is highlighted by the error bar. Furthermore, for the two samples that were subjected to the 
highest impact velocities, reliable C-scan data were unavailable. Consequently, the damage was estimated from the micrographs of polished sections assuming a circular area of damage (see Figure 9).

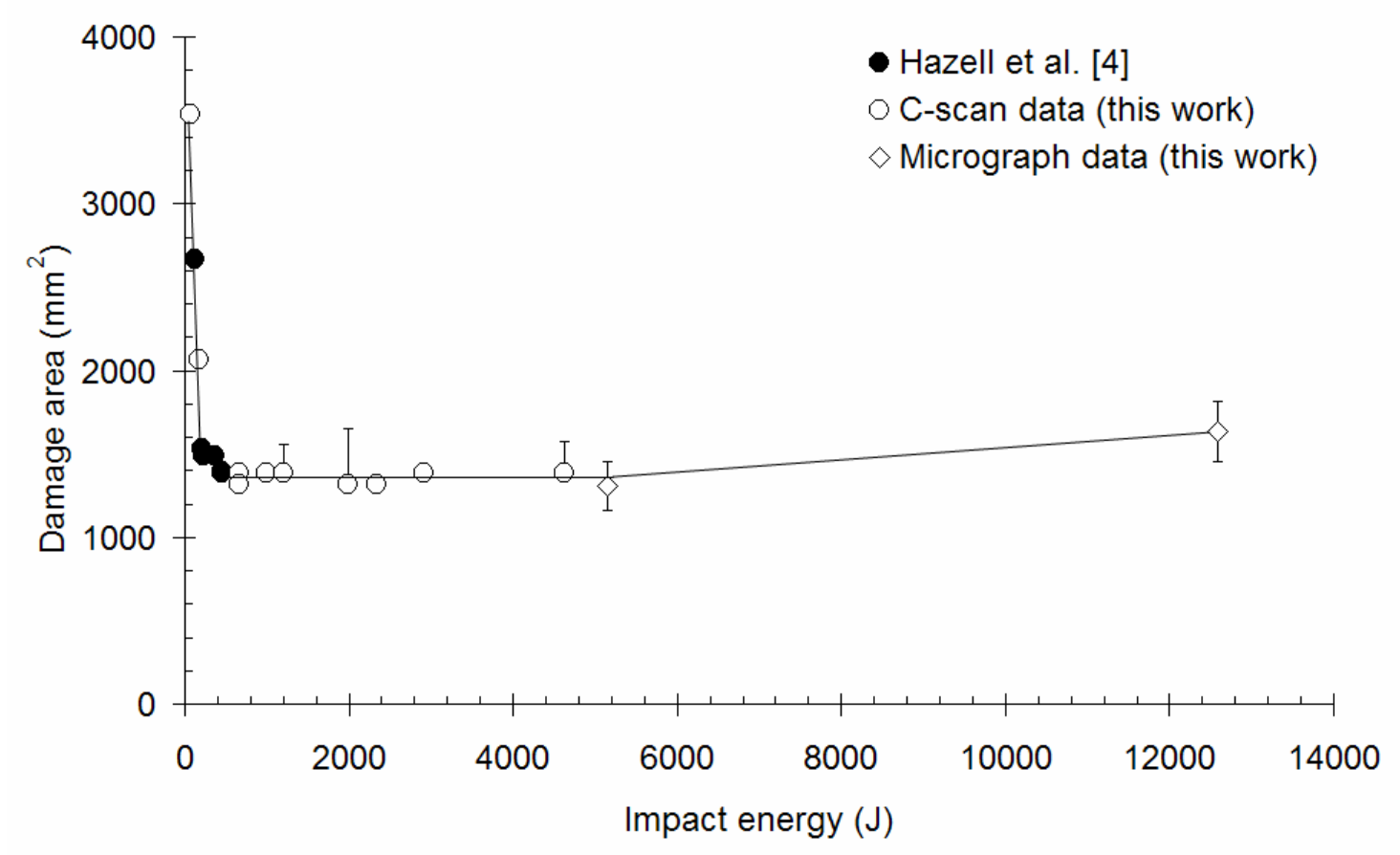

Figure 8: Damage area measured by C-scan for each of the impacted targets.

From Figure 8, the level of damage is constant between an impact energy of c. $500 \mathrm{~J}$ and $5000 \mathrm{~J}$ despite the energy dissipated by the CFRP laminate increasing (see Figure 2). This implies that the increase in the energy dissipated by the CFRP laminate is not related to the degree of damage as measured by the C-scan. We should point out that the data point at the impact test of $12600 \mathrm{~J}(1875 \mathrm{~m} / \mathrm{s})$ is somewhat higher than the horizontal line of best fit drawn at c. $1350 \mathrm{~mm}^{2}$ damage area. This implies that, perhaps, there is a small increase in the level of damage area at this elevated velocity. Nevertheless it is still considerably less than the damage area seen at much lower impact energies such 
as at $180 \mathrm{~J}$ where c. $2100 \mathrm{~mm}^{2}$ of damage was observed. Furthermore, analyses of the polished sections revealed that the through-thickness level of damage was largely similar for the $1199 \mathrm{~m} / \mathrm{s}$ and $1875 \mathrm{~m} / \mathrm{s}$ firings. However, the volume of damage appeared less with the $1875 \mathrm{~m} / \mathrm{s}$ impact test when compared to the lower velocity test data. This is shown in Figure 9. We should also point out that the pattern of damage observed here differed substantially from the through-thickness damage reported in [4] where petalling or plug formation was apparent. In this impact velocity range, the through-thickness delamination in the composite occurred consistently throughout the entire thickness of the CFRP laminate. For the sample struck at $1199 \mathrm{~m} / \mathrm{s}$ consistent delamination was seen in the first three laminae whereas little damage occurred in the layers four to eight. On the other hand, the remaining layers exhibited extensive delamination and matrix cracking. Furthermore, it was observed for the sample struck at $1875 \mathrm{~m} / \mathrm{s}$ that extensive damage occurred in the initial laminae and the rear laminae. As observed in the previous impacted and analysed samples [4], delamination and matrix cracks were seen between the different laminates and also between different fibre tows. Unlike the targets impacted at the lower energies [4], the greatest extension of damage was not located towards the rear of the targets but rather it was more centrally located. 


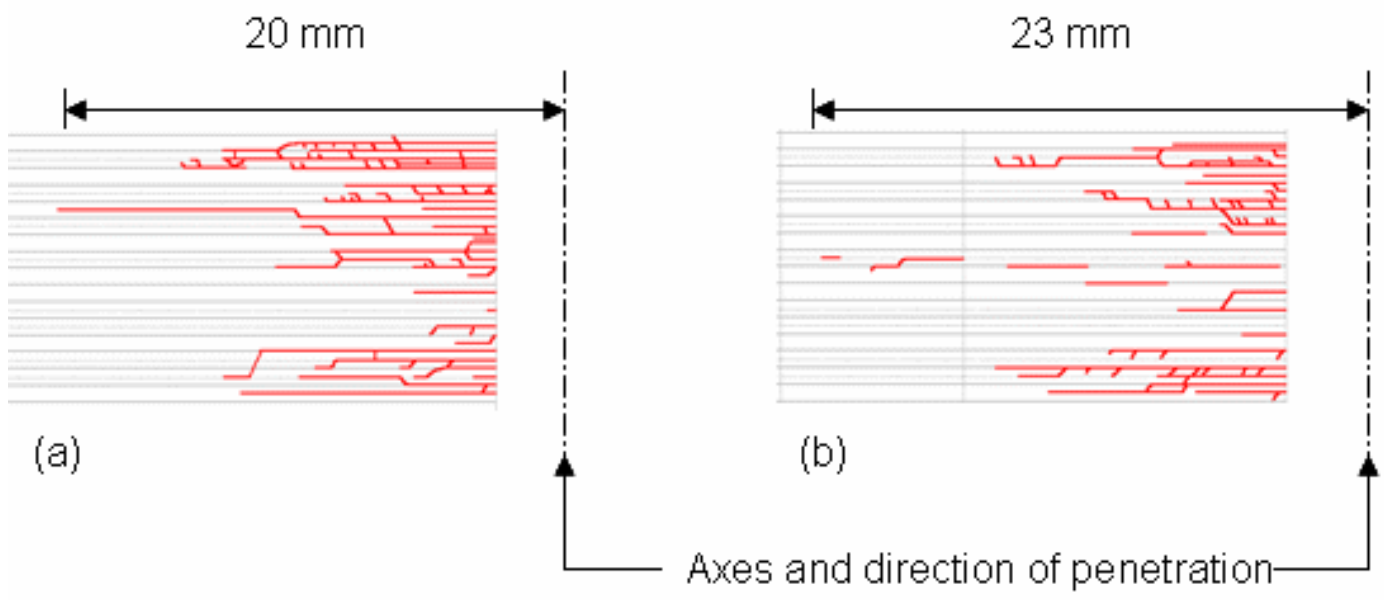

Figure 9: Traced detail of damage from targets that have been subjected to impact at: (a) $5150 \mathrm{~J}$ (1199 m/s) and, (b) $12600 \mathrm{~J}(1875 \mathrm{~m} / \mathrm{s})$.

Despite the level of damage remaining broadly constant, the size of the penetration hole was seen to increase as the impact energy was increased. In Figure 10 we have plotted an estimate of the area of the hole formed by the projectile as a function of the impact energy. In this case the estimated area is merely given by squaring the maximum diameter (d) of the hole as measured from the impact face. For one experiment, a single bursting element from the breach firing mechanism followed the projectile down the gun barrel and enlarged the hole that was formed. This data-point has been included for completeness. Above c. $660 \mathrm{~J}$, the hole diameter was larger than the diameter of the projectile $(12 \mathrm{~mm})$ and the square of the diameter increased linearly with impact energy. From the firings conducted below an impact energy of $660 \mathrm{~J}$, the hole diameter was very small (c. $3.9 \mathrm{~mm}$ ) indicating that significant relaxation of the carbonfibre tows had occurred leading the cavity-closure. No clear hole was formed at an impact energy of $71 \mathrm{~J}$ as the projectile was stopped. As the impact energy was increased, more material was separated from the target and pushed away from the region of the 
penetration. Therefore, a contribution to the increase in energy dissipated by the laminate at the higher velocities can be explained in terms of the formation of the penetration channel and the subsequent increase in hole size.

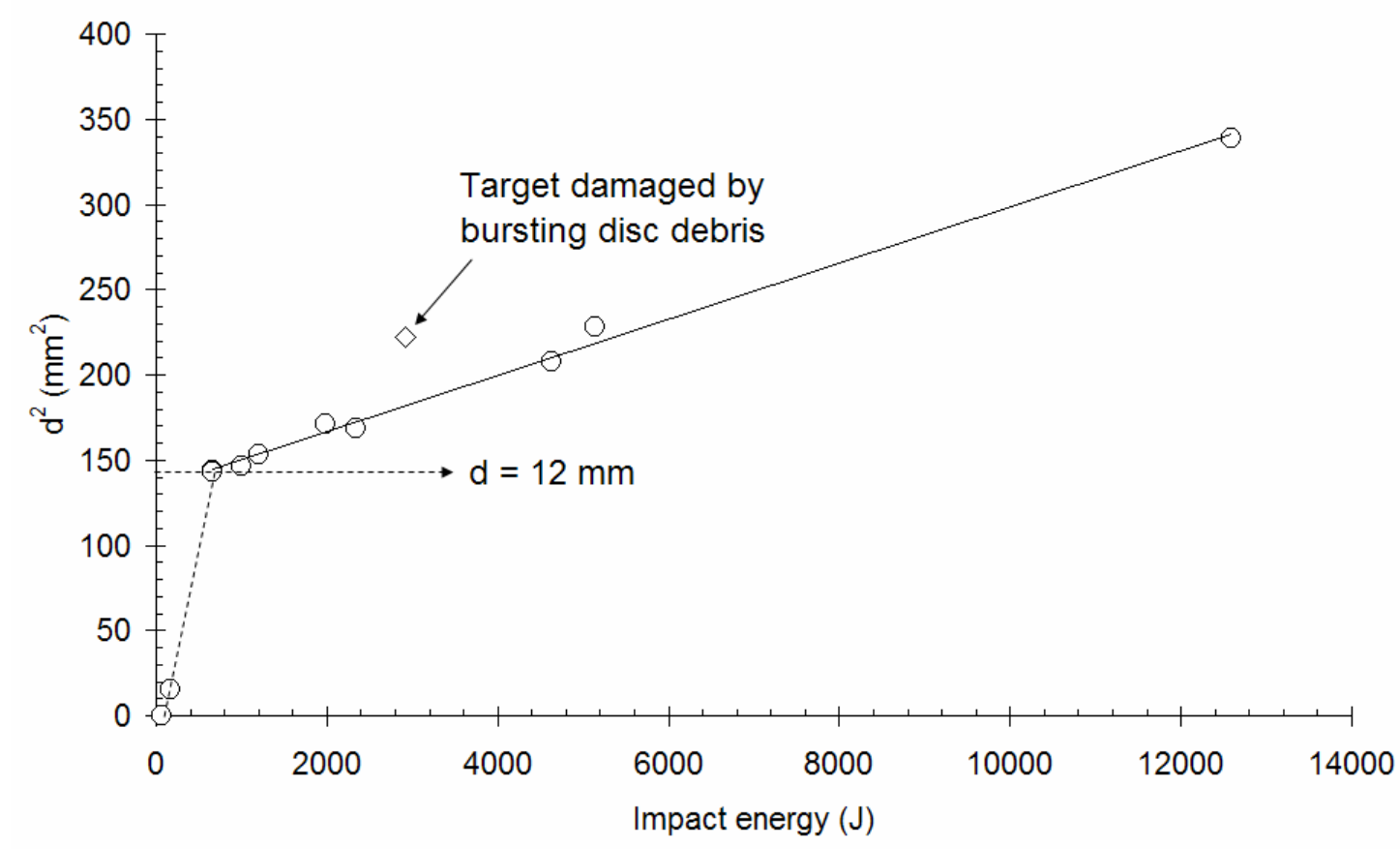

Figure 10: Increase in the area of the cavity formed by the impact of the steel sphere.

It should be pointed out that during the course of these experiments, deformation of the steel sphere was observed. However, three projectiles were soft-captured in cotton rags to assess the degree of deformation caused by the impact. It was noted that for an impact velocity of $744 \mathrm{~m} / \mathrm{s}$, the degree of deformation for this relatively soft projectile was c. $0.3 \mathrm{~mm}$ as measured along the minor axis. An unfired projectile was subsequently placed in-between the platens of an Instron 4206 universal testing machine to assess the energy required to deform the projectile by $0.3 \mathrm{~mm}$. We concede that this is a relatively crude estimate of the energy required to deform the sphere as it negates the high strain rate effects that the sphere would have been subjected to during impact. Nevertheless, the 
energy required to deform the sphere was calculated at $1 \mathrm{~J}$ and represents a tiny fraction of the $424 \mathrm{~J}$ that was expended at this impact velocity. Consequently, the energy expended by the sphere is small in comparison to that of the target. The majority of the energy that is dissipated in the CFRP laminate is from the comminution of the CFRP material and in the kinetic energy transferred to the particulated material. Given the low trans-laminar strength of these CFRP laminates [17] and the weakness of the exposed fibres caused by the matrix particulation (Figure 6), the majority of the energy would be given up in the kinetic energy of the particulates. It is also interesting to note that this is also seen in the ballistic impact of unconfined ceramics where relatively little energy is required to create new fracture surfaces and instead a large portion of kinetic energy of the projectile is transferred to the ejected fragments of the ceramic [20]. This is particularly important in analytical model formulations based on energy conservation where perforation is predicted. 


\section{CONCLUSIONS}

A series of impact test have been carried out on a woven CFRP laminate that was manufactured using the RTM process. In this work we have identified that:

(1) Using data from [4], the ballistic limit of the 6-mm thick CFRP laminate subjected to impact and penetration by a $12 \mathrm{~mm}$ steel sphere is between $141 \mathrm{~m} / \mathrm{s}$ and $179 \mathrm{~m} / \mathrm{s}$; the perforation threshold energy lies in-between $71 \mathrm{~J}$ and $115 \mathrm{~J}$;

(2) The percentage of kinetic energy dissipated by the CFRP laminate approached an asymptotic level at relatively high (c. > $2000 \mathrm{~J}$ ) impact energies;

(3) There is a rapid rise in the diameter of the cavity formed with impact energy until an impact energy of $662 \mathrm{~J}$ is reached;

(4) Above an impact energy of $662 \mathrm{~J}$, the area of the perforation hole appeared to scale linearly with impact energy.

(5) Although the percentage of kinetic energy dissipated by the CFRP laminate appears constant at the higher levels of impact, the degree of damage as measured by C-scan is constant. This implies that the increase in the energy dissipated by the CFRP laminate is independent to the degree of damage due to delamination. Consequently, the increase in the energy transfer can be attributed to the expansion of the cavity and more importantly, the kinetic energy of the particulates. 


\section{ACKNOWLEDGEMENTS}

The authors would like to thank Mr Keith Campbell of Short Brothers plc, Belfast, UK for supplying the CFRP panels. We also would like to thank Drs John Rock and Jonathan Painter for their valuable time on the Scanning Electron Microscopes. We gratefully acknowledge the UK MoD and the EPSRC who funded part of this work under GR/S33994/01. We also acknowledge DOSG (UK) who funded the development of ELVIS - one of the guns used in this experimental programme. Finally, we are grateful of the support of the staff at COTEC (Cranfield Ordnance Test and Evaluation Centre) in helping with two of the experiments. 


\section{REFERENCES}

(1) Cantwell WJ, Morton J. Comparison of the low and high velocity impact response of CFRP. Composites 1989;20(6): 545-551.

(2) Silvestrov VV, Plastanin AV, Gorshkov NN. Hypervelocity impact on laminate composite panels. Int J. Impact Engng 1995;17:751-762.

(3) Ryan S, Schaefer F, Riedel W. Numerical simulation of hypervelocity impact on CFRP/Al HC SP spacecraft structures causing penetration and fragment ejection. Int J Impact Engng 2006;33:703-712.

(4) Hazell PJ, Kister G, Bourque P, Cooper G. Normal and oblique penetration of woven CFRP laminates by a high velocity steel sphere. Compos Part A: Appl S 2008; 39:866874.

(5) Tanabe Y, Aoki M, Fujii K, Kasano H, Yasuda E. Fracture behavior of CFRPs impacted by relatively high-velocity steel sphere. Int J Impact Engng 2003;28:627-642.

(6) Tanabe Y, Aoki M. Stress and strain measurements in carbon-related materials impacted by a high velocity steel sphere. Int J Impact Engng 2003; 28: 1045-1059. (7) Fujii K, Aoki M, Kiuchi N, Yasuda E, Tanabe Y. Impact perforation of CFRPs using high-velocity steel sphere. Int J Impact Engng 2002; 27:497-508.

(8) Hammond RI, Proud WG, Goldrein HT, Field JE. High-resolution optical study of the impact of carbon-fibre reinforced polymers with different lay-ups. Int J Impact Engng 2004;30:69-86. 
(9) Lopez-Puente J, Zaera R, Navarro C. Experimental and numerical analysis of normal and oblique ballistic impacts on thin carbon/epoxy woven laminates. Compos Part AAppl S 2008;39:374-387.

(10) Lopez-Puente J, Zaera R, Navarro C. The effect of low temperature on the intermediate and high velocity impact response of CFRPs. Compos Part B-Eng 2002; 33:559-566.

(11) Hazell PJ, Stennett C, Cooper G. The shock and release behaviour of an aerospacegrade cured aromatic amine epoxy resin. Polym Compos 2008; 29 (10): 1106-1110. DOI 10.1002/pc.20614 .

(12) Millett JCF, Bourne NK, Meziere YJE, Vignjevic R, Lukyanov A. The effect of orientation on the shock response of a carbon fibre-epoxy composite. Compos Sci Technol 2007;67:3253-3260.

(13) Hazell PJ, Stennett C, Cooper G. The effect of specimen thickness on the shock propagation along the in-fibre direction of an aerospace-grade CFRP laminate. In press Compos Part A-Appl S (2009). DOI: 10.1016/j.compositesa.2008.11.002.

(14) ASTM Standard D 3171-06. Standard Test Methods for Constituent Content of Composite Materials. ASTM International, 2006.

(15) Cryogenic materials data handbook, Volume 1, Sections A-C, Air Force Materials Laboratory, Air Force Command, Wright-Patterson Air Force Base, Ohio, AFML-TDR64-280, 1970.

(16) Lee S-WR, Sun CT. Dynamic penetration of graphite/epoxy laminates impacted by a blunt-ended projectile. Compos Sci Technol 1993;49:369-380. 
(17) Cantwell WJ, Morton J. Impact perforation of carbon fibre reinforced plastics. Compos Sci Technol 1990;38:119-141.

(18) Hatta H, Goto K, and Aoki T. Strengths of C/C composites under tensile, shear, and compressive loading: Role of interfacial shear strength, Composites Science and Technology 2005; 65:2550-2562.

(19) HexFlow ${ }^{\circledR}$ RTM 6 product data sheet. Hexcel, Duxford, Cambridge, UK, CB2 4QD. (20) Woodward RL, Gooch Jr WA, O'Donnell RG, Perciballi WJ, Baxter BJ, Pattie SD. A study of fragmentation in the ballistic impact of ceramics. Int. J. Impact Engn 1994;15: 605-618. 